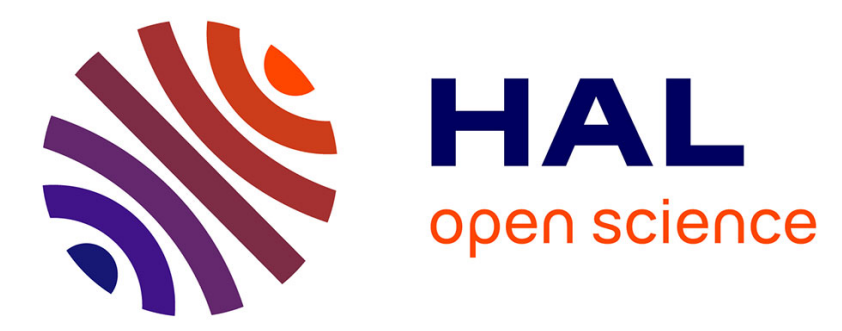

\title{
A Bipotential Method Coupling Contact, Friction and Adhesion
}

\author{
N Terfaya, A Berga, M Raous
}

\section{To cite this version:}

N Terfaya, A Berga, M Raous. A Bipotential Method Coupling Contact, Friction and Adhesion. International Review of Mechanical Engineering (I.RE.M.E.), 2015, 9 (4), pp.341-352. 10.15866/ireme.v9i4.5841. hal-01258316

\section{HAL Id: hal-01258316 https://hal.science/hal-01258316}

Submitted on 18 Jan 2016

HAL is a multi-disciplinary open access archive for the deposit and dissemination of scientific research documents, whether they are published or not. The documents may come from teaching and research institutions in France or abroad, or from public or private research centers.
L'archive ouverte pluridisciplinaire HAL, est destinée au dépôt et à la diffusion de documents scientifiques de niveau recherche, publiés ou non, émanant des établissements d'enseignement et de recherche français ou étrangers, des laboratoires publics ou privés. 


\title{
A bipotential Method Coupling Contact, Friction and adhesion
}

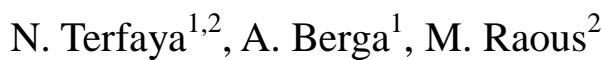

\begin{abstract}
The paper is related to the analysis and the modeling of structural interface behaviors when unilateral contact, friction and adhesion interact. Among the contact models in literature, the model developed by Raous, Cangémi, Cocou and Monerie (RCCM model) is retained. It consists to include strict unilateral contact to avoid interpenetration, initial adhesion progressively decreases when the load increases, and Coulomb's friction which is progressively activated when adhesion decreases. Because of its implicit character, the Coulomb friction law with adhesion is non-associated, and the notion of superpotential with normality rule cannot be used anymore. In the present work, to overcome this non-associated character, a specific potential adapted to coupling unilateral contact, friction and adhesion is build and named bipotential. A numerical model is proposed and improved to solve the boundaries values problem. The algorithm is implemented in the finite element code SYMEF which has been developed at the University of Bechar (Algeria). A comparative study is made between the bipotential model and the previously developed RCCM model. The numerical results show that, this approach is robust and efficient in terms of numerical stability, precision convergence and CPU time compared to the RCCM model.
\end{abstract}

Keywords: Contact, Friction, Adhesion, Bipotential Method, Convex Analysis

\section{Introduction}

In almost all mechanical and structural engineering systems, there exists the situation in which one deformable body comes in contact with another. Due to their complexity, the contact phenomenon between solids is rarely taken into account in structural analysis. These complexity arises due to the inherent nonlinearity of the problem and the multivalued nature of the contact and friction relations, which poses serious mathematical and computational difficulties. Indeed, the introduction of friction between the contacting bodies is another important source of nonlinearity [1]-[4]. The nonlinear and irreversible nature of the contact problem requires a reliable and stable numerical algorithm for achieving iteration convergence and solution accuracy. With the advent of more powerful computers the onus has been placed on the numerical method for the solution of contact problems which involves systems of inequalities or nonlinear equation. In recent years, tremendous progress has been made in the solution of frictional contact problems with the finite element method. A large number for numerical techniques used to enforce contact constraints have been presented in the literature. These algorithms can be grouped as follows: the penalty function method [1]-[4], the flexibility method [5],[6], the mathematical programming method [7]-[9], the Lagrangian multiplier method [10],[11] and the augmented Lagrangian method [12]-[16]. In the last decade of the twentieth century, De Saxcé and Feng have proposed a new bipotential method derived from a new theory called the implicit standard materials (ISM). In this novel model a new formulation of augmented Lagrangian was presented [17],[18]. In the contact bipotential model, the unilateral contact and the friction are coupled and the formulation leads to a unique inequality and a single displacement variational principle [17],[18]. Using an Uzawa algorithm [17]-[19], the obtained saddle point problem is solved by means of a prediction-correction process. Furthermore, the prediction-correction solution algorithm combined with projection leads to a sequence of minimization problems under constraints which are reduced to regular minimization problems when a Lagrange multiplyer is introduced [19]. The frictional contact problem is then treated in a reduced system. Generally, the numerical treatment of contact problems involves the definition of interface laws, and the development of algorithms. In order to simulate the behaviour of complex interfaces, a cohesive model (RCC model) coupling adhesion, friction and unilateral contact was proposed in [20] and extended in [21] (the RCCM model). This model is based on the adhesion intensity variable, introduced by Fremond [22],[23], which is a surface damage variable and takes its values between 0 and 1 ( 0 is no adhesion and 1 is total adhesion). This model gives a smooth transition from total adhesion to the usual Coulomb friction law with unilateral contact. Because of the non smooth character of the interface law set as multivalued applications (strict Signorini conditions and strict Coulomb law after 
collapse of the adhesion), the analysis regards non smooth mechanics. The aim of the present paper is to apply the bipotential method for unilateral contact with the coupling of, friction, and adhesion. Adhesion and friction are strongly coupled through a specific compliance with damage that acts only in traction or shear and that disappears when the contact displacements increase. This insures a continuous transition between total adhesive and pure frictional states [24],[25]. The developed algorithm is implemented into the finite element code SYMEF where the contact simulation, based on the bipotentiel method [17],[18] has been improved by Berga and Terfaya at the University of Bechar [26]-[28]. Some numerical examples are performed in this study to show the validity of the model.

\section{Unilateral contact and Coulomb}

\section{friction laws}

Before presenting the frictional contact laws, some basic definitions and notations are set up. Let $\mathrm{A}$ and $\mathrm{B}$ be two deformable bodies coming in contact at a point $\mathrm{P}$ (Fig. 1). P' is the target point defined by the normal projection of $\mathrm{P}$ on $\mathrm{B}$. Under the small displacement assumption, we define $\Gamma_{c}$ the contact zone between $\mathrm{A}$ and $\mathrm{B}, \boldsymbol{n}$ the normal unit outer vector of $\mathrm{B}$ at $\mathrm{P}^{\prime}$ and $\boldsymbol{T}(\boldsymbol{t} 1, \boldsymbol{t} 2)$ the orthogonal plane to $\boldsymbol{n}$ in $\mathfrak{R}^{3}$. The vector $\boldsymbol{n}$ and the tangential plane $\boldsymbol{T}$ define the local coordinate system. Furthermore, we denote $\boldsymbol{R}$ the contact reaction acting at $\mathrm{P}$ ' from $\mathrm{B}$ onto $\mathrm{A}$ and $\dot{\boldsymbol{u}}_{\boldsymbol{1}}, \dot{\boldsymbol{u}}_{\boldsymbol{2}}$ are respectively, the instantaneous velocities of the particles of $\mathrm{A}$ and $\mathrm{B}$ passing at point $\mathrm{P}$ and $\mathrm{P}$ '. The relative velocity is $\dot{\boldsymbol{u}}=\dot{\boldsymbol{u}}_{1}-\dot{\boldsymbol{u}}_{2}$, where the superposed dot denotes the time derivative. In the local coordinate system, the relative velocity and the contact reaction are decomposed into normal and tangential components as follow:

$$
\begin{aligned}
\dot{\boldsymbol{u}} & =\dot{\boldsymbol{u}}_{\boldsymbol{t}}+\dot{u}_{n} \boldsymbol{n} \\
\boldsymbol{R} & =\boldsymbol{R}_{\boldsymbol{t}}+R_{n} \boldsymbol{n}
\end{aligned}
$$

where $\dot{u}_{n}$ is the normal relative velocity, $\dot{u}_{t}$, the sliding velocity, $R_{n}$ the contact force and $\boldsymbol{R}_{t}$ the friction force.
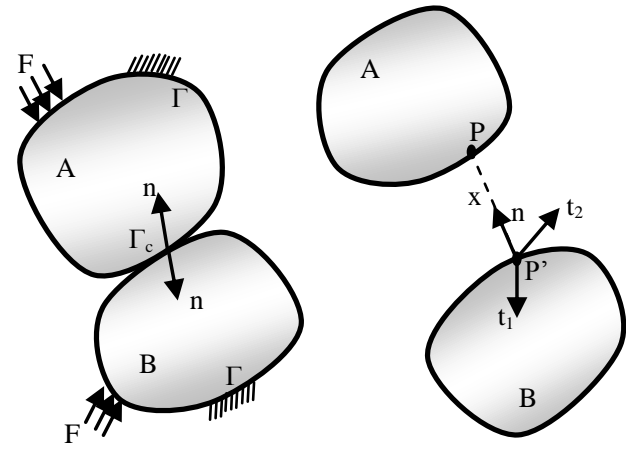

Fig. 1 : Kinematics of contact
The unilateral contact law impose three conditions: a geometric condition of non-penetration, a static condition of no-adhesion and a mechanical complementarity condition. These conditions are referred to Signorini conditions and are written in terms of the signed contact distance $\boldsymbol{x}_{n}$ and the normal contact force $R_{n}$ as follow [1]-[26]:

$$
x_{n} \geq 0 ; R_{n} \geq 0 ; \text { and } R_{n} x_{n}=0
$$

Where $\boldsymbol{x}_{\boldsymbol{n}}$ denotes the magnitude of the gap between the contact node and the target surface;

$$
\mathrm{x}_{\mathrm{n}}=\mathrm{h}_{0}+u_{n}
$$

Denoting by $\mathrm{h}_{0}$ the initial gap between the solids $\mathrm{A}$ and

B. The unilateral contact condition (3) turns into:

$$
u_{n} \geq 0 ; R_{n} \geq 0 \text {; and } R_{n} u_{n}=0
$$

For bodies in contact $\left(u_{n}=0\right)$, the unilateral contact law (Signorini's conditions) can be expressed equivalently in terms of velocities:

$$
\dot{u}_{n} \geq 0 ; R_{n} \geq 0 ; \text { and } R_{n} \cdot \dot{u}_{n}=0
$$

The formulation of Signiorini's condition in terms of velocities allow us to write the complete frictional contact law when bodies are in contact . Regarding the dry friction law, it is generally characterized by a kinematic slip rule. Let the closed convex set $K_{\mu}$ be the isotropic Coulomb's cone, which defines the set of admissible forces satisfying:

$$
K_{\mu}=\left\{\boldsymbol{R} \in \mathfrak{R} \text { such that } \boldsymbol{f}(\boldsymbol{R})=\left\|\boldsymbol{R}_{t}\right\|-\mu . R_{n} \leq 0\right\}
$$

Where $R_{n}, \boldsymbol{R}_{t}$ are respectively the normal and tangential contact force and $\mu$ is the friction coefficient of the Coulomb law. By combining the Signorini's condition to the sliding rule, we can define the complete frictional contact law. This complex dissipative law is described by three contact statues: no contact, contact with sticking and contact with sliding. The problem can be stated as: if $R_{n}=0$ then $\dot{u}_{n} \geq 0 \Rightarrow$ separating (no contact) if $R \in$ int $K_{\mu}$ then $\quad \dot{u}=0 \Rightarrow$ sticking; if $R_{n} \geq 0$ and $\mathrm{R} \in \partial K_{\mu}(f(R)=0)$ then :

$\dot{u}_{n} \geq 0$ and $\exists \lambda \geq 0$ such that $\dot{\boldsymbol{u}}_{t}=-\lambda \frac{\boldsymbol{R}_{t}}{\left\|\boldsymbol{R}_{t}\right\|} \Rightarrow$ sliding

where 'int $K_{\mu}$ ' and ' $\partial K_{\mu}$ ' denote the interior and the boundary of $K_{\mu}$. In the above formulation, the first and second part, shows that the frictional contact constitutive model has a multivalued character.

\section{The RCCM model}

The RCC model (Raous- Cangémi- Cocou) has been first given in [24], [25], and then extensively presented in [20]. It has been extended to the present form (RCCM model) including progressive friction with the term $(1-\beta)$ in [21], [29]. The RCCM model has been successfully used for composite materials (matrix-fibre interfaces, ductile cracks) [21], steel- concrete interfaces (pull out of reinforced concrete) [30], interfaces in masonry construction [31], and pile- soil interface [32]. The 
RCCM model consider both unilateral contact, Coulomb friction, and adhesion. It is based on interface damage.

In the framework of continuum thermodynamics, the contact zone is considered as a material surface and the local constitutive laws are derived by choosing two specific surface potentials: the free energy and the dissipation potential [20], [25]. The adhesion is characterized in this model by the internal variable $\beta$, introduced by Frémond [22], [23], which denotes the intensity of adhesion. It is a surface damage variable that takes its value between zero (no adhesion) and one (perfect adhesion). The introduction of a damageable stiffness of the interface ensures a smooth transition between the two contact conditions (initial adhesion and final frictional sliding). The behaviour of the interface is described by the following relations, where equation (9) gives the unilateral contact with adhesion, (10) gives the Coulomb friction with adhesion and (11) gives the evolution of the adhesion intensity $\beta$. Initially, when the adhesion is complete, the interface is elastic as long as the energy threshold $w$ is not reached. After that, damage of the interface occurs gradually and consequently, on the one hand, the adhesion intensity $\beta$ and the apparent stiffness $\beta^{2} C_{\mathrm{n}}$ and $\beta^{2} C_{\mathrm{t}}$ decrease, and on the other hand, friction begins to operate. When the adhesion is completely broken $(\beta=0)$, we get the classical Signorini problem with Coulomb friction. The model is then written as follows:

- unilateral contact (Signorini conditions) with adhesion:

$R_{n}-C_{n} u_{n} \beta^{2} \geq 0 ; \quad u_{n} \leq 0 ; \quad\left(\mathrm{R}_{n}-C_{n} u_{n} \beta^{2}\right) \cdot u_{n}=0$

- Coulomb friction with adhesion:

$$
\left\{\begin{array}{l}
\boldsymbol{R}_{t}^{r}=C_{t} \boldsymbol{u}_{t} \beta^{2} ; R_{n}^{r}=R_{n} \\
\left\|\boldsymbol{R}_{t}-\boldsymbol{R}_{t}^{r}\right\| \leq \mu(1-\beta)\left|R_{n}-C_{n} u_{n} \beta^{2}\right|
\end{array}\right.
$$

Where the superscript $(.)^{\mathrm{r}}$ means reversible part, with:

$$
\left\{\begin{aligned}
\text { if }\left\|\boldsymbol{R}_{t}-\boldsymbol{R}_{t}^{r}\right\| & <\mu(1-\beta)\left|R_{n}-C_{n} u_{n} \beta^{2}\right| \Rightarrow \dot{\boldsymbol{u}}_{t}=0 \\
\text { if }\left\|\boldsymbol{R}_{t}-\boldsymbol{R}_{t}^{r}\right\| & =\mu(1-\beta)\left|R_{n}-C_{n} u_{n} \beta^{2}\right| \\
& \Rightarrow \exists \lambda \geq 0, \dot{\boldsymbol{u}}_{t}=-\lambda \frac{\left(\boldsymbol{R}_{t}-\boldsymbol{R}_{t}^{r}\right)}{\left\|\boldsymbol{R}_{t}-\boldsymbol{R}_{t}^{r}\right\|}
\end{aligned}\right.
$$

- Evolution of the adhesion intensity:

$$
\begin{cases}\alpha \dot{\beta}=-\left(w-\left(C_{n} u_{n}^{2}+C_{t} u_{t}^{2}\right) \beta\right)^{-} & \text {if } \beta \in[0,1[ \\ \alpha \dot{\beta} \leq-\left(w-\left(C_{n} u_{n}^{2}+C_{t} u_{t}^{2}\right) \beta\right)^{-} & \text {if } \beta=1\end{cases}
$$

Where $(\mathrm{x})^{-}$denotes the negative part of $\mathrm{x}$ such that : $(\mathrm{x})^{-}=\max (0 ;-\mathrm{x}) ; \forall \mathrm{x} \in \mathfrak{R}$. Hence, the constitutive parameters of the model are:

- $C_{n}$ and $C_{t}$, the initial stiffness of the interface,

- $\mathrm{w}$ is the decohesion energy (as long as that threshold is not reached, adhesion stays to be complete and the behavior of the interface is elastic with the initial stiffness $\mathrm{C}_{\mathrm{n}}$ and $\mathrm{C}_{\mathrm{t}}$ ),

- $\mu$ is the friction coefficient,
- $\alpha$ is the viscosity associated to the evolution of the adhesion.

\section{The bipotential model}

In order to generalize the concept of pseudo-potential, introduced by J.-J. Moreau for multivalued constitutive laws [17], to non associated laws, G. De Saxcé [17], [18] introduced the concept of bipotential and the Implicit Standard Materials (ISM). Bipotentials are non-smooth mechanics tools, which allows modelling various non associative multivalued constitutive laws of dissipative materials (friction contact, soils, cyclic plasticity of metals, damage). The bipotential theory, based on an extension of Fenchels inequality, leads to a succesful new writing of the constitutive laws of some dissipative materials and permits to recover a flow rule subnormality for non-standard behaviors, specially soils and unilateral contact with dry friction [17],[18], [33]-[35].

\section{IV.1. Concept of bipotential}

Let us consider a material system $\mathrm{S}$ described by a space $\mathrm{V}$ of generalized velocities $\dot{\boldsymbol{u}}$, carrying a structure of vector space over the field of real numbers $\mathfrak{R}$ and a dual vector space $\mathbf{F}$ of force $\boldsymbol{R}$ is associated to $\mathbf{V}$ by a bilinear form $(\dot{\boldsymbol{u}}, \boldsymbol{R}) \rightarrow \dot{\boldsymbol{u}} . \boldsymbol{R}$.

This bilinear form define the power of dissipation. The RCCM model presented above is a non-standard dissipative laws. Because of its implicit character, this law is non-associated, and the notion of a superpotential with normality rule, used in classical plasticity, cannot be used anymore. According to De Saxcé and Z-Q. Feng [17], [18], the normal dissipation rule can be generalized by constructing a unique function depending on the velocities $\dot{\boldsymbol{u}}$ and on the forces $\boldsymbol{R}$, called bipotential and here denoted $b$ :

$$
b: \boldsymbol{V} \times \boldsymbol{F} \mapsto[-\infty,+\infty]:(\dot{\boldsymbol{u}}, \boldsymbol{R}) \mapsto b(\dot{\boldsymbol{u}}, \boldsymbol{R})
$$

$b$ is biconvex, namely convex with respect to $\dot{\boldsymbol{u}}$, when $\boldsymbol{R}$ is fixed, and convex with respect to $\boldsymbol{R}$, when $\dot{\boldsymbol{u}}$ is fixed. Furthermore, the bipotential satisfies the fundamental inequality:

$$
\forall(\dot{\boldsymbol{u}}, \boldsymbol{R}) \in \boldsymbol{V} \times \boldsymbol{F}, b(\dot{\boldsymbol{u}}, \boldsymbol{R}) \geq \dot{\boldsymbol{u}} . \boldsymbol{R}
$$

This generalization of the Fenchel inequality is the cornerstone of the formulation. The couples $(\dot{u}, R)$ are said extremal when equality is reached:

$$
b(\dot{\boldsymbol{u}}, \boldsymbol{R})=\dot{\boldsymbol{u}} . \boldsymbol{R}
$$

One can show, that the extremal couple is related by the dissipative law. Then, any extremal pair satisfies:

$$
\left\{\begin{array}{lc}
a) b\left(\dot{\boldsymbol{u}}^{\prime}, \boldsymbol{R}\right)-b(\dot{\boldsymbol{u}}, \boldsymbol{R}) \geq \boldsymbol{R} .\left(\dot{\boldsymbol{u}}^{\prime}-\dot{\boldsymbol{u}}\right) & \dot{\boldsymbol{u}} \in \boldsymbol{V} \\
b) b\left(\dot{\boldsymbol{u}}, \boldsymbol{R}^{\prime}\right)-b(\dot{\boldsymbol{u}}, \boldsymbol{R}) \geq \dot{\boldsymbol{u}} .\left(\boldsymbol{R}^{\prime}-\boldsymbol{R}\right) & \boldsymbol{R}^{\prime} \in \boldsymbol{F}
\end{array}\right.
$$

This is equivalent to the differential inclusions characterizing an implicit subnormality law:

$$
\dot{\boldsymbol{u}} \in \partial_{\boldsymbol{R}} b(\dot{\boldsymbol{u}}, \boldsymbol{R}) \text { and } \boldsymbol{R} \in \partial_{\dot{\boldsymbol{u}}} b(\dot{\boldsymbol{u}}, \boldsymbol{R})
$$


The relations (16) define a multivalued constitutive law and its inverse.

\section{IV.2. Bipotential coupling contact, friction and adhesion}

This formulation is based on the works of Raous et al [20] and Raous and Monerie [21] on the soft coupling between adhesion and frictional contact. The following thermodynamic variables are introduced: the relative displacements $\left(\dot{u}_{n}, \dot{\boldsymbol{u}}_{\boldsymbol{t}}\right)$ and the adhesion intensity $\beta$ are chosen as the state variables, and the contact force $\boldsymbol{R}$ and a decohesion force $\boldsymbol{G}_{\boldsymbol{\beta}}$, as the associated thermodynamic forces such that:

$$
\boldsymbol{G}_{\boldsymbol{\beta}}=\boldsymbol{w}-\left(C_{n} u_{n}^{2}+C_{t} \boldsymbol{u}_{\boldsymbol{t}}^{2}\right) \boldsymbol{\beta}
$$

Based on the work of M. Jean, V. Acaray et Y. Monerie [36]- [39], we have introduced the following change of variables to take into account the adhesion in contact problems :

$$
\overline{\boldsymbol{R}}=\boldsymbol{R}-\boldsymbol{R}_{\text {adh }}
$$

$\boldsymbol{R}_{\text {adh }}$ which is quite generally an additional resistance force to normal or tangential separation whose intensity decreases with increased debonding. The interfacial forces $\boldsymbol{R}_{\boldsymbol{a d h}}$ induced by the adhesion, are introduced under the form of a compliance law depending on the current state of adhesion $\beta$ and characterized by the initial stiffness $\mathrm{C}_{\mathrm{n}}$ and $\mathrm{C}_{\mathrm{tth}}$ such that:

$$
R_{a d h n}=\int_{\Gamma_{c}} C_{n} \beta^{2} u_{n} d \Gamma_{c} \text { and } \boldsymbol{R}_{\text {adht }}=\int_{\Gamma_{c}} C_{t} \beta^{2} \boldsymbol{u}_{t} d \Gamma_{c}
$$

The Coulomb's cone $K_{\bar{\mu}}$ is defined as follow:

$$
K_{\bar{\mu}}=\left\{\left(\bar{R}_{n}, \overline{\boldsymbol{R}}_{t}\right), /|| \overline{\boldsymbol{R}}_{t} \|-\bar{\mu}\left|\bar{R}_{n}\right| \leq 0\right\}
$$

where: $\bar{R}_{n}=R_{n}-R_{a d h n}, \quad \overline{\boldsymbol{R}}_{t}=\boldsymbol{R}_{t}-\boldsymbol{R}_{a d h t}, \quad \bar{\mu}=\mu .(1-\beta)$ and $\partial K_{\bar{\mu}}(\overline{\boldsymbol{R}})$ is the sliding surface.

The classical Coulomb's friction condition is recovered by setting $\beta=0(\bar{\mu}=\mu)$ and we get the usual definition of Coulomb's cone. The Coulomb's friction law with adhesion, as written in relations (9), (10a) and (10b), exhibits an aspect similar to the non-associated flow rule in plasticity. Indeed, during sliding, contact is maintained. The normal relative velocity $\dot{u}_{n}$ is null and not related to the normal component of the reaction $\bar{R}_{n}$ through normality. That means that the relative velocity $\dot{u}$ is not normal to the Coulomb's cone. If we regard the contact force $\overline{\boldsymbol{R}}$ and the velocity $\dot{u}$ as conjugate quantities of each other, the normality will not occur since it would require that the velocity would have a normal separating component. Furthermore, the relative velocities $\dot{\boldsymbol{u}}$ (when $\dot{u}_{n} \geq 0$ ) are admissible at the apex of the Coulomb's cone, which indicate that the normality rule will not occur and the concept of pseudo-potential cannot be used. We conclude that Coulomb's frictional contact law with adhesion is non-associated. A change of variable for the sliding velocity is introduced and the following bipotential (21) is constructed. It is composed of two parts, one controlling the interface law and the other one controlling the adhesion evolution:

$$
\begin{aligned}
b\left(-\dot{\boldsymbol{u}}, \dot{\beta}, \overline{\boldsymbol{R}}, \boldsymbol{G}_{\boldsymbol{\beta}}\right)= & I_{K_{\bar{\mu}}}(\overline{\boldsymbol{R}})+I_{\mathfrak{R}^{-}}\left(-\dot{u}_{n}\right)+ \\
& \mu(1-\beta) \cdot \bar{R}_{n}\left\|-\dot{\boldsymbol{u}}_{\boldsymbol{t}}\right\|+\frac{\alpha \dot{\beta}^{2}}{2}+I_{C^{-}}(\dot{\beta})+\frac{\left(\boldsymbol{G}_{\boldsymbol{\beta}}^{-}\right)^{2}}{2 \alpha}
\end{aligned}
$$

where $\dot{\boldsymbol{u}}$ is the relative velocity, $\beta$ the intensity of adhesion taking value between 0 and $1, \overline{\boldsymbol{R}}$ the contact force and $\boldsymbol{G}_{\boldsymbol{\beta}}$ the thermodynamic force associated to the state variable $\beta$. The parameter $\alpha$ is the adhesion viscosity and $\mu$ is the friction coefficient. $I_{s}$ denotes the indicator function of the specified sets S. In (21), the indicator functions $I_{\mathfrak{R}^{-}}$impose the unilateral conditions and $I_{C^{-}}$imposes the condition $\dot{\beta} \leq 0$ which means that in the present model, the evolution of the intensity of adhesion is an irreversible and dissipative process depending on $\beta$ and the adhesion can only decrease.

It has been shown that this bipotential verifies the suitable properties of biconvexity and satisfies (13), (14) and (15). Then the contact laws with adhesion can be, respectively, written in the following compact forms of implicit subnormality rules or differential inclusion rules $-\dot{\boldsymbol{u}} \in \partial_{\overline{\boldsymbol{R}}} b(-\dot{\boldsymbol{u}}, \overline{\boldsymbol{R}}) ; \quad \overline{\boldsymbol{R}} \in \partial_{-\dot{\boldsymbol{u}}} b(-\dot{\boldsymbol{u}}, \overline{\boldsymbol{R}})$

where $\partial_{x} b(-\dot{\boldsymbol{u}}, \overline{\boldsymbol{R}})$ denotes the sub-differential of $b$ with respect to the variable $x$. The contact law and the equation for the evolution of $\beta$, which are explicitly given by expression (9), (10a), (10b) and (11), are deduced from the state and complementary laws expressed in term of differential inclusions:

$$
\begin{aligned}
& \bar{R}_{n} \in \partial_{-\dot{u}_{n}} b\left(-\dot{\boldsymbol{u}}, \dot{\beta}, \overline{\boldsymbol{R}}, \boldsymbol{G}_{\boldsymbol{\beta}}\right) \Rightarrow R_{n}-C_{n} \beta^{2} u_{n} \in \partial_{-\dot{u}_{n}} I_{\mathfrak{R}^{-}}\left(-\dot{u}_{n}\right) \\
& \overline{\boldsymbol{R}}_{\boldsymbol{t}} \in \partial_{-\dot{\boldsymbol{u}}_{t}} b\left(-\dot{\boldsymbol{u}}, \dot{\beta}, \overline{\boldsymbol{R}}, \boldsymbol{G}_{\boldsymbol{\beta}}\right) \Rightarrow \\
& \Rightarrow \boldsymbol{R}_{\boldsymbol{t}}-C_{t} \beta^{2} \boldsymbol{u}_{\boldsymbol{t}} \in \mu(1-\beta)\left|R_{n}-C_{n} \beta^{2} u_{n}\right| \partial_{-\dot{\boldsymbol{u}}_{t}}\left\|-\dot{\boldsymbol{u}}_{\boldsymbol{t}}\right\| \\
& \boldsymbol{G}_{\boldsymbol{\beta}} \in \partial_{\dot{\beta}} b\left(-\dot{\boldsymbol{u}}, \dot{\boldsymbol{\beta}}, \overline{\boldsymbol{R}}, \boldsymbol{G}_{\boldsymbol{\beta}}\right) \Rightarrow \boldsymbol{G}_{\boldsymbol{\beta}} \in \alpha \dot{\beta}+\partial_{\dot{\beta}} I_{C^{-}}(\dot{\beta}) \\
& \Rightarrow \boldsymbol{G}_{\boldsymbol{\beta}}-\alpha \dot{\beta} \in \partial_{\dot{\beta}} I_{C^{-}}(\dot{\beta})
\end{aligned}
$$

The inverse law derives also from the bipotential $b\left(-\dot{\boldsymbol{u}}, \dot{\beta}, \overline{\boldsymbol{R}}, \boldsymbol{G}_{\boldsymbol{\beta}}\right)$ :

$$
\begin{aligned}
& -\dot{\boldsymbol{u}}_{\boldsymbol{t}} \in \partial_{\overline{\boldsymbol{R}}_{t}} b\left(-\dot{\boldsymbol{u}}, \dot{\beta}, \overline{\boldsymbol{R}}, \boldsymbol{G}_{\boldsymbol{\beta}}\right) \Rightarrow-\dot{\boldsymbol{u}}_{\boldsymbol{t}} \in \partial_{\overline{\boldsymbol{R}}_{t}} I_{K_{\bar{\mu}}}(\overline{\boldsymbol{R}}) \\
& -\dot{u}_{n} \in \partial_{\bar{R}_{n}} b\left(-\dot{\boldsymbol{u}}, \dot{\beta}, \overline{\boldsymbol{R}}, \boldsymbol{G}_{\boldsymbol{\beta}}\right) \Rightarrow-\dot{u}_{n} \in \partial_{\bar{R}_{n}} I_{K_{\bar{\mu}}}(\overline{\boldsymbol{R}})+\mu(1-\beta)\left\|-\dot{u}_{\boldsymbol{t}}\right\| \\
& \Rightarrow-\dot{u}_{n}-\mu(1-\beta)\left\|-\dot{\boldsymbol{u}}_{\boldsymbol{t}}\right\| \in \partial_{\bar{R}_{n}} I_{K_{\bar{\mu}}}(\overline{\boldsymbol{R}})
\end{aligned}
$$

$\dot{\beta} \in \partial_{\boldsymbol{G}_{\boldsymbol{\beta}}} b\left(-\dot{\boldsymbol{u}}, \dot{\beta}, \overline{\boldsymbol{R}}, \boldsymbol{G}_{\boldsymbol{\beta}}\right) \Rightarrow \dot{\beta}=-\frac{\left(\boldsymbol{G}_{\boldsymbol{\beta}}^{-}\right)}{\alpha}$

We note here that the expression (23) is equivalent to the unilateral contact condition [40],[41], then we obtain :

$$
\begin{aligned}
& -\dot{u}_{n} \geq 0 ;\left(R_{n}-C_{n} \beta^{2} u_{n}\right) \geq 0 ; \\
& \quad \text { and }\left(R_{n}-C_{n} \beta^{2} u_{n}\right) \cdot\left(-\dot{u}_{n}\right)=0
\end{aligned}
$$


Expression (29) is the unilateral contact law with adherence. When $\beta=0$, the Signorini conditions is recovered. With similar reasoning, (24) leads to an equivalent relation as follow:

$$
\left\{\begin{aligned}
&\left\|\boldsymbol{R}_{\boldsymbol{t}}-C_{t} \beta^{2} \boldsymbol{u}_{\boldsymbol{t}}\right\| \leq \mu(1-\beta)\left|R_{n}-C_{n} \beta^{2} u_{n}\right| \\
&\left\|\boldsymbol{R}_{\boldsymbol{t}}-C_{t} \beta^{2} \boldsymbol{u}_{\boldsymbol{t}}\right\|<\mu(1-\beta)\left|R_{n}-C_{n} \beta^{2} u_{n}\right| \Rightarrow \dot{\boldsymbol{u}}_{\boldsymbol{t}}=0 \\
&\left\|\boldsymbol{R}_{\boldsymbol{t}}-C_{t} \beta^{2} \boldsymbol{u}_{\boldsymbol{t}}\right\|=\mu(1-\beta)\left|R_{n}-C_{n} \beta^{2} u_{n}\right| \Rightarrow \\
& \exists \lambda>0 \text { such as } \dot{\boldsymbol{u}}_{\boldsymbol{t}}=-\lambda \frac{\left(\boldsymbol{R}_{\boldsymbol{t}}-C_{t} \beta^{2} \boldsymbol{u}_{\boldsymbol{t}}\right)}{\left\|\boldsymbol{R}_{\boldsymbol{t}}-C_{t} \beta^{2} \boldsymbol{u}_{\boldsymbol{t}}\right\|}
\end{aligned}\right.
$$

It is the friction law with adhesion, and when $\beta=0$ we have the usual Coulomb friction law. Using (28), expression of $\dot{\beta}$, and by introducing the expression (17) for $G_{\beta}$, a study on variable $\beta$ which holds in [0,1[ makes it possible to express the adhesion evolution in the following form:

$$
\left\{\begin{array}{l}
\alpha \dot{\beta}=-\left[w-\left(C_{n} u_{n}^{2}+C_{t} \boldsymbol{u}_{t}^{2}\right) \beta\right]^{-} \text {if } \beta \in[0,1[ \\
\alpha \dot{\beta} \leq-\left[w-\left(C_{n} u_{n}^{2}+C_{t} u_{t}^{2}\right)\right]^{-} \quad \text { if } \beta=1
\end{array}\right.
$$

Where: $\forall \mathrm{x} \in \mathfrak{R},(\mathrm{x})^{-}=\max (0 ;-\mathrm{x})$; the negative part of $\mathrm{x}$. The relations (29) to (31) show clearly that the RCCM model, coupling contact, friction and adherence expressed by (9), (10a), (10b) and (11) can be obtained from a unique function that is the bipotential $b\left(-\dot{\boldsymbol{u}}, \dot{\beta}, \overline{\boldsymbol{R}}, \boldsymbol{G}_{\boldsymbol{\beta}}\right)$.

\section{Local algorithm}

In the method described above, the unilateral contact and friction are coupled to the adhesion through a contact bipotential. Unlike the RCCM model using two inequalities and two separate algorithms for the unilateral contact and friction, this model leads to a single inequality and one variational principle. The constitutive law coupling contact, friction and adhesion is represented by inequalities and the contact potential is non-differentiable and the non-associativity of the constitutive law is responsible for numerical troubles. The bipotentiel $b\left(-\dot{\boldsymbol{u}}, \dot{\boldsymbol{\beta}}, \overline{\boldsymbol{R}}, \boldsymbol{G}_{\boldsymbol{\beta}}\right)$ represented by the expression (21), where the adhesion is combined with the friction and the unilateral conditions, has a differentiable part and another part with no-differentiable potentials as the case of the contact and friction with adhesion. The variation of the intensity of adhesion governed by a differentiable expression will not induce any difficulties. Indeed the values of $\beta$ can be obtained from the differential system (31) by a numerical integration (Method of Euler, $\theta$-Method...etc.) for displacements increments provided at the beginning step of time. In order to avoid non-diferentiable potentials that occur in contact problems with adhesion, it is convenient to use the Augmented Lagrangian Method [14],[15]. The application of the augmented Lagrangian method to the contact laws leads to implicit equations of projection onto the Coulomb friction cone. The method leads to the following implicit equations:

$$
\overline{\boldsymbol{R}}=\operatorname{Proj}\left(\boldsymbol{\tau}, K_{\bar{\mu}}\right)
$$

where $\tau$ is the modified augmented contact reaction defined by:

$$
\boldsymbol{\tau}=\overline{\boldsymbol{R}}-\rho\left[\dot{\boldsymbol{u}}_{\boldsymbol{t}}+\left(\dot{u}_{n}+\bar{\mu} \cdot\left\|\dot{\boldsymbol{u}}_{\boldsymbol{t}}\right\|\right) \cdot \boldsymbol{n}\right]
$$

The equality (32) means that $\overline{\boldsymbol{R}}$ is the projection of $\boldsymbol{\tau}$ onto the closed convex Coulomb cone $K_{\bar{\mu}}$. The parameter $\rho$ is a real positive numbers that can be chosen in order to ensure numerical convergence, such as the maximum value of the diagonal terms of the local contact stiffness matrix or chosen according to the eigenvalue of the contact flexibility matrix. In our analysis, the factor $\rho$ is calculated using the diagonal terms of the flexibility matrix W:

$$
\rho=1 / \min \left(W_{n n}, W_{t t}\right)
$$

The flexibility matrix $\mathrm{W}$, is defined in the local coordinate system by $\mathrm{W}=\mathrm{H}^{\mathrm{T}} \mathrm{K}^{-1} \mathrm{H}$. Where $\mathrm{K}$ denotes the stiffness matrix and $\mathrm{H}$ the rotation matrix between the local frame $\left(\boldsymbol{t}_{1}, \boldsymbol{t}_{2}, \boldsymbol{n}\right)$ and global one $(\mathrm{X} ; \mathrm{Y} ; \mathrm{Z})$. The local problem is treated in a reduced system by means of reliable and efficient predictor-corrector algorithm. A saddle point problem is obtained and an iterative Uzawa algorithm can be used to solve the implicit equation (32) [19]. This algorithm has been successfully applied by Feng [42] and Feng et al. [43]. A prediction-correction process combined with projection leads to a sequence of minimization problems under constraints which are reduced to regular minimization problems when a Lagrange multiplyer is introduced. The Uzawa algorithm leads to an iterative process involving one predictorcorrector step:

$$
\begin{aligned}
& \text { - Predictor: } \boldsymbol{\tau}^{i+1}=\overline{\boldsymbol{R}}^{i}-\rho\left[\dot{\boldsymbol{u}}_{t}^{i}+\left(\dot{u}_{n}^{i}+\bar{\mu}\left\|\dot{\boldsymbol{u}}_{t}^{i}\right\|\right) \cdot \boldsymbol{n}\right] \\
& \text { - Corrector: } \overline{\boldsymbol{R}}^{i+1}=\operatorname{proj}\left(\boldsymbol{\tau}^{i+1}, K_{\bar{\mu}}\right)
\end{aligned}
$$

According to (32) and corrector steps, the process is iterative and at the $(i+1)^{\text {th }}$ iteration, the local stage can be summarized by:

- Predictor: $\boldsymbol{\tau}^{i+1}=\overline{\boldsymbol{R}}^{i}-\rho\left[\dot{\boldsymbol{u}}_{t}^{i}+\left(\dot{u}_{n}^{i}+\bar{\mu}\left\|\dot{\boldsymbol{u}}_{t}^{i}\right\|\right) \cdot \boldsymbol{n}\right]$

- Corrector:

if $\bar{\mu}\left\|\tau_{t}^{j+1}\right\|<-\tau_{n}^{j+1}$ then $\quad \overline{\boldsymbol{R}}^{j+1}=0$ (separating) (38a)

else if $\left\|\tau_{t}^{j+1}\right\| \leq \bar{\mu} \tau_{n}^{j+1} \quad$ then $\bar{R}^{j+1}=\tau^{j+1}$ (sticking) (38b)

$\bar{R}^{j+1}=\tau^{j+1}-\left(\frac{\left\|\tau_{t}^{j+1}\right\|-\bar{\mu} \tau_{n}^{j+1}}{1+\bar{\mu}^{2}}\right)\left(\frac{\tau_{t}^{j+1}}{\left\|\tau_{t}^{j+1}\right\|}-\bar{\mu} \cdot n\right)($ sliding) (38c)

The iterative solution procedure involving contact modelling with adhesion is written as below: 
1. Read the data: geometry, mesh, material properties, boundary conditions,

2. Compute the stiffness matrix $\mathbf{K}$ and the external force vector $\mathbf{F}_{\text {ext }}$,

2.1 Modify $\mathbf{K}$ and $\mathbf{F}_{\text {ext }}$ for essential boundary conditions

3. For each time step It

3.1 Detect contact conditions (local frame, gap vector. . .)

3.2 Compute the flexibility matrix $\mathrm{W}$,

3.3 Solve $\mathbf{K} . \Delta \mathbf{u}=\mathbf{F}_{\text {ext }}$

3.4 For each adhesion step Ia

3.4.1 Compute reaction forces $\overline{\boldsymbol{R}}$ by local algorithm

For each contact node nc

- Predictor:

$$
\begin{aligned}
& \boldsymbol{\tau}^{i+1}=\overline{\boldsymbol{R}}^{i}-\rho\left[\dot{\boldsymbol{u}}_{\boldsymbol{t}}^{i}+\left(\dot{u}_{n}^{i}+\bar{\mu}\left\|\dot{\boldsymbol{u}}_{t}^{i}\right\|\right) \cdot \boldsymbol{n}\right] \\
& \text { - Corrector } \overline{\boldsymbol{R}}^{i+1}=\operatorname{proj}\left(\boldsymbol{\tau}^{i+1}, K_{\bar{\mu}}\right)
\end{aligned}
$$

3.4.2 Compute reaction $\mathbf{R}:\left(R_{n}, \boldsymbol{R}_{t}\right)$ from (18)

3.4.3 Time integration of equation of $\beta$ evolution

3.5 Solve $\mathbf{K} \cdot \Delta \mathbf{u}=\mathbf{F}_{\text {ext }}+\mathbf{R}$

3.6 Update displacements,

3.7 Compute stresses and strains

4. Update step count, if simulation is note achieved, go to 3

\section{Numerical results}

The algorithms presented above have been implemented and tested in the finite element code SYMEF developed by Berga and Terfaya at FIMAS laboratory, at the University of Bechar [26]-[28]. Many application examples involving frictional contact with adhesion, in static or quasi-static cases, have been carried out using the present method. In order to validate the developed model, we propose to study two different benchmarks for simulating delamination [44]-[47] which have been developed in the framework of a joint project with the LCPC laboratory (Laboratoire Central des Ponts et Chaussées )[45] focusing on adhesion and gluing in civil engineering. The presented model is compared with the RCCM model developed by Raous et al. and implemented in the GYPTIS90 code (LMA Marseille) [48]. To show the performance of the present approach, we give the CPU time and number of iterations provided by the two codes. The adhesion intensity $\beta$, the tangential displacement $\boldsymbol{u}_{\boldsymbol{t}}$ and the normal displacement $u_{n}$ are presented along the interface. It is noted that these analysis were performed on a PC (Hp Pavilion G6 i5).

\section{VI.1. Delamination of a thin layer of aluminium submitted to vertical loading}

The first example concerns a 2D plane strain delamination of $a$ thin layer of Aluminium with
$\mathrm{L}=50 \mathrm{~mm} ; \mathrm{h}=2.5 \mathrm{~mm}$, initially adhered to a rigid support [45]-[47]. The geometric configuration, the boundary conditions and finite element mesh used are given on Figure 2. A vertical prescribed displacement (v) is applied incrementally at point $\mathrm{A}$ with a maximum value of $\mathrm{v}=0.3 \mathrm{~mm}$ (in $10 \mathrm{sec}$ ), divided into 210 increments. The elastic behaviour is assumed. Only the behaviour of the interface is considered with dissipative law $(\alpha \neq 0)$. The same contact stiffness was chosen for the normal and the tangential interface behavior : $C_{n}=C_{t}=C$. The characteristics of this example are given as below:

Young's modulus: $\mathrm{E}=6.9 \mathrm{E}+04 \mathrm{MPa}$;

Poisson's ratio: $\quad v=0.333$.

The decohesion energy: $\mathrm{w}=1 . \mathrm{E}-06 \mathrm{~mJ} / \mathrm{mm}^{2}$;

The initial stiffnesses of the interface:

$\mathrm{C}_{\mathrm{n}}=\mathrm{C}_{\mathrm{t}}=2 . \mathrm{E}+05 \mathrm{MPa} / \mathrm{mm}$

The interface viscosity: $\alpha=1 \mathrm{Ns} / \mathrm{mm}$;

The friction coefficient: $\mu=0.2$

The initial conditions are supposed to be complete adhesion $(\beta=1)$ and zero displacement $\left(u_{n}=0, \boldsymbol{u}_{t}=0\right)$.

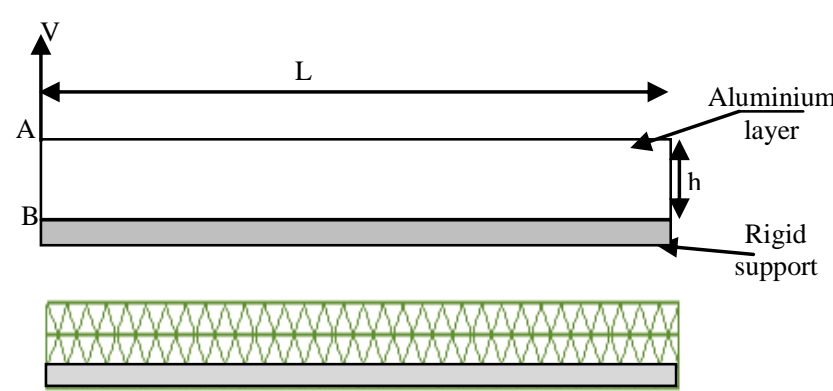

Fig 2. Geometry and finite element mesh

For comparison purpose, we have used the same mesh. The finite element discretization includes 130 three-node isoparametric plane strain elements and 100 nodes. The interface consists of 33 contact nodes. The successive deformed meshes are displayed in Figure 3 for three time step $\mathrm{t} 1, \mathrm{t} 2$ and $\mathrm{t} 3$.

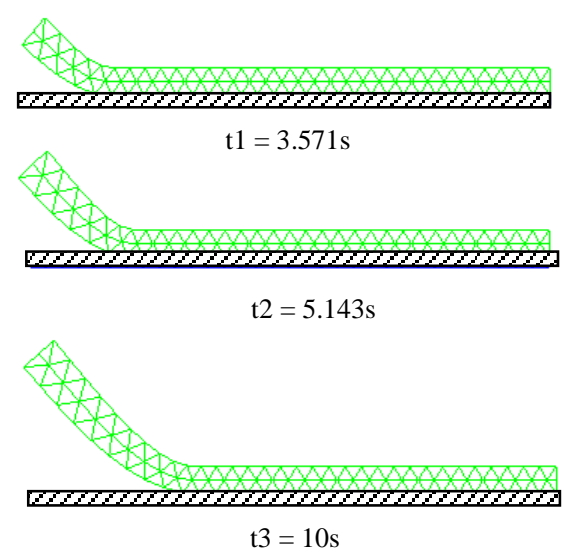

Fig 3. Deformed meshes

Fig. 4, presents the results given by the models : RCCM and the bipotential, for $\mathrm{t} 1=3.571 \mathrm{~s}$ and $\mathrm{t} 2=5.143 \mathrm{~s}$. The 
contact condition is presented for the given steps of the loading. The values of the adhesion intensity $\beta$, the tangential displacement $\boldsymbol{u}_{t}$ and the normal displacement $u_{n}$ are plotted along the interface.
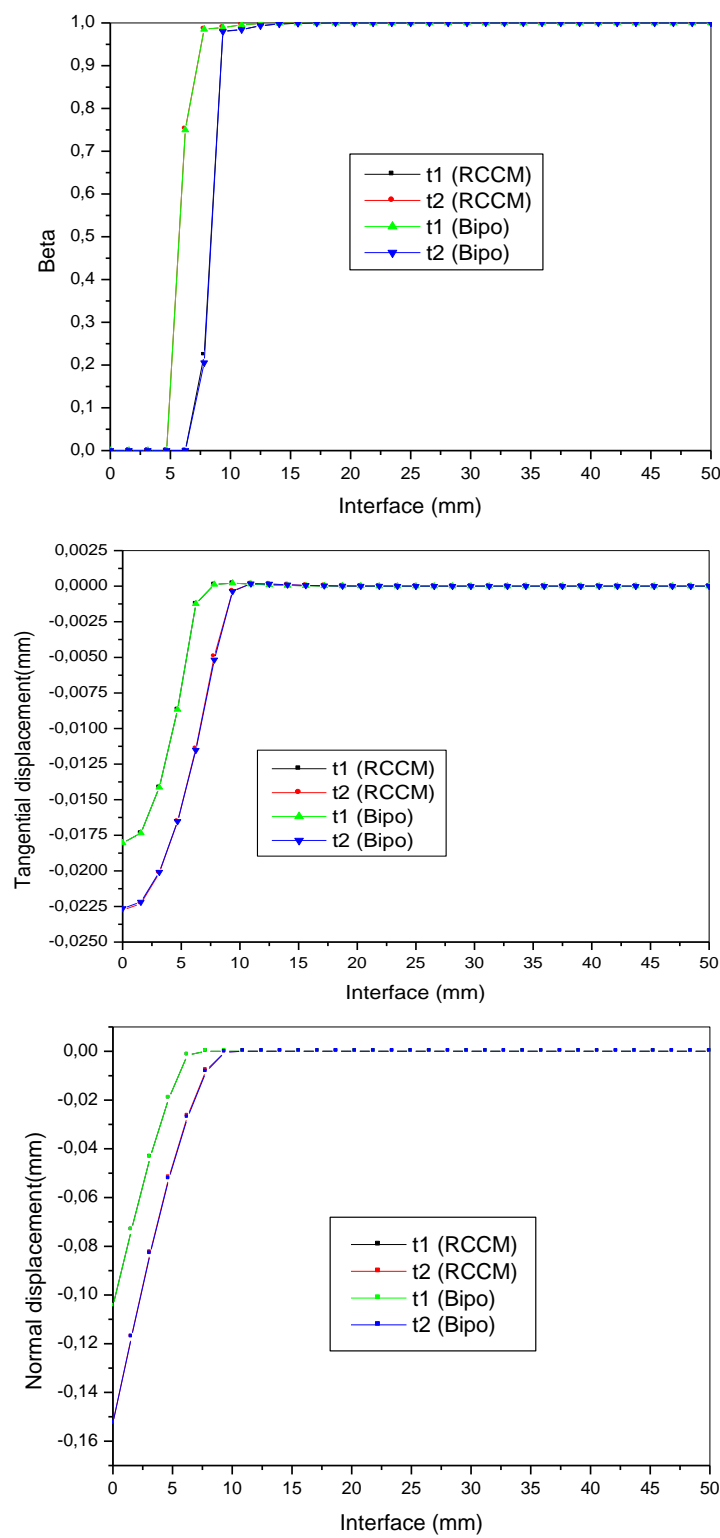

Fig. 4 : The adhesion intensity $\beta$, the tangential displacement $\boldsymbol{u}_{t}$ and the normal displacement $u_{n}$ along the interface for loading step: $\mathrm{t} 1, \mathrm{t} 2$

The results are almost the same as shown in Fig. 4 and a good agreement can be observed between the bipotential model results and the RCCM ones. Fig. 5 shows the evolution of the normal adhesive reaction $\boldsymbol{R}_{\boldsymbol{a d h}}$ and the adhesion intensity $\beta$ versus time at points $B$ of the interfaces.
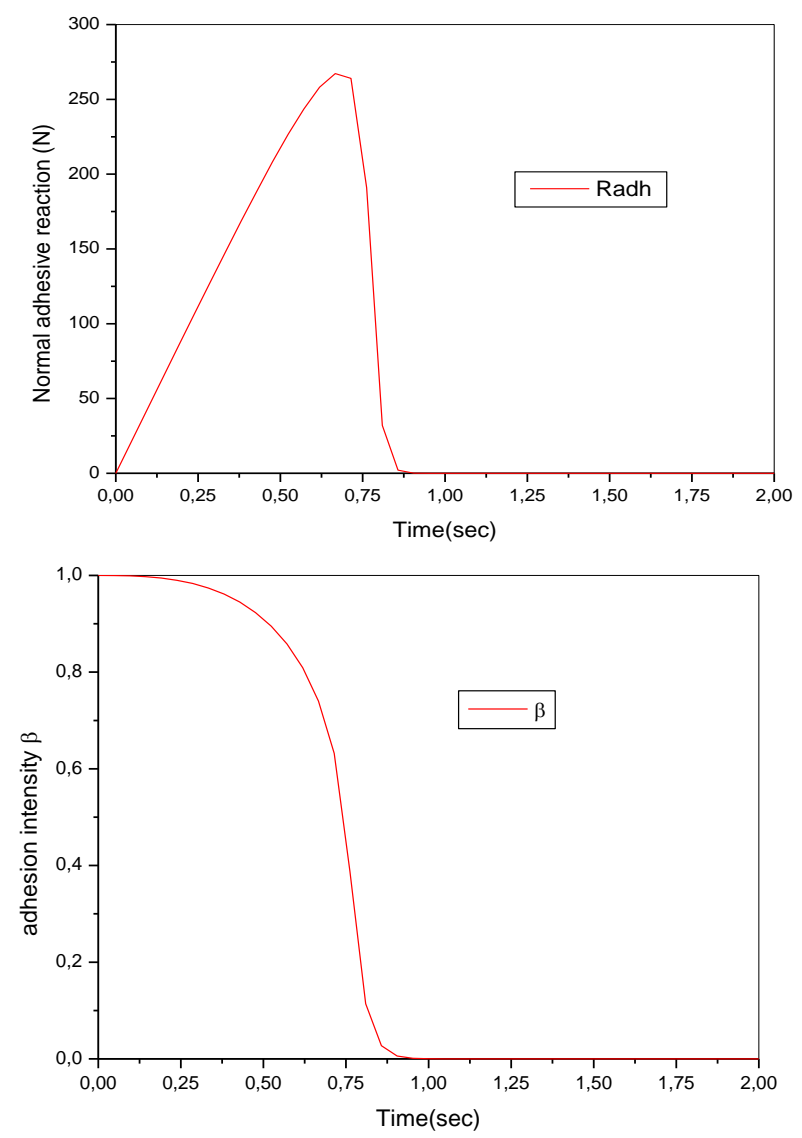

Fig. 5 : Evolution of the normal adhesive reaction $\boldsymbol{R}_{\boldsymbol{a d h}}$ and the adhesion intensity $\beta$

Under the imposed displacement, an adhesive resistance $\left(R_{a d h n}=\int_{\Gamma_{c}} C_{n} \beta^{2} u_{n} d \Gamma_{c}\right)$ is mobilized (elasticity with damage). The intensity of adhesion starts to decrease $\dot{\beta} \leq 0 \quad(0<\beta<1)$ when the displacement is sufficiently large such that the elastic energy becomes larger than the limit of adhesion energy w. Evolution of the adhesion is then governed by (31). When adhesion is totally broken $(\beta=0)$, the classical Signorini problem is obtained (6). The performance of the present algorithm in terms of CPU time, the number of iterations related to the calculation of $\beta$ and contact reactions compared to RCCM's model, is reported in Table 1.

It shows that, globally, the RCCM algorithm needs more iterations than the bipotential algorithm, particularly for contact iterations. These results show the robustness and accuracy of the proposed method. 
TABLE 1.

COMPARISON OF CPU TIME

\begin{tabular}{|c|c|c|c|c|c|c|c|c|c|}
\hline \multirow{2}{*}{ Model } & \multirow{2}{*}{ Parameters } & \multicolumn{7}{|c|}{ Steps } & \multirow{2}{*}{$\begin{array}{c}\text { GLOBAL CPU } \\
\text { (s) }\end{array}$} \\
\hline & & 1 & 10 & 40 & 60 & 100 & 150 & 200 & \\
\hline \multirow{3}{*}{$\begin{array}{l}\widetilde{\Omega} \\
\Omega \\
\Omega\end{array}$} & $\beta$ Iterations & 1 & 3 & 14 & 7 & 3 & 2 & 4 & \multirow{3}{*}{$2^{\prime}: 41 \mathrm{~s} .663 \mathrm{c}$} \\
\hline & $\begin{array}{l}\text { Contact } \\
\text { Iterations }\end{array}$ & 132 & 133 & 132 & 132 & 132 & 132 & 197 & \\
\hline & $\mathrm{CPU}(\mathrm{s})$ & 0.294 & 0.189 & 0.182 & 0.187 & 0.210 & 0.191 & 0.299 & \\
\hline \multirow{3}{*}{ 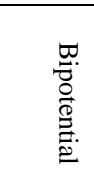 } & $\beta$ Iterations & 1 & 2 & 6 & 6 & 2 & 2 & 2 & \multirow{3}{*}{ 1' $6 \mathrm{~s} 80 \mathrm{c}$} \\
\hline & $\begin{array}{l}\text { Contact } \\
\text { Iterations }\end{array}$ & 7 & 7 & 8 & 8 & 8 & 8 & 8 & \\
\hline & CPU (s) & 0.15 & 0.11 & 0.11 & 0.11 & 0.11 & 0.11 & 0.12 & \\
\hline
\end{tabular}

\section{VI.2. Shear delamination of a block of aluminium}

To reinforce the role of friction, one studied the case of an Aluminum block compressed on a rigid plane. Initially the system is in total adhesion [44],[45]. The block is submitted to a displacement imposed on its left lateral edge. The loading is of $\mathrm{u}=20 \mathrm{~mm}$ in $10 \mathrm{~s}$. On the upper face of the block a vertical displacement of $\mathrm{v}=-0.5 \mathrm{~mm}$ is applied. Geometry, boundary conditions, and finite element mesh are given on Fig 6.
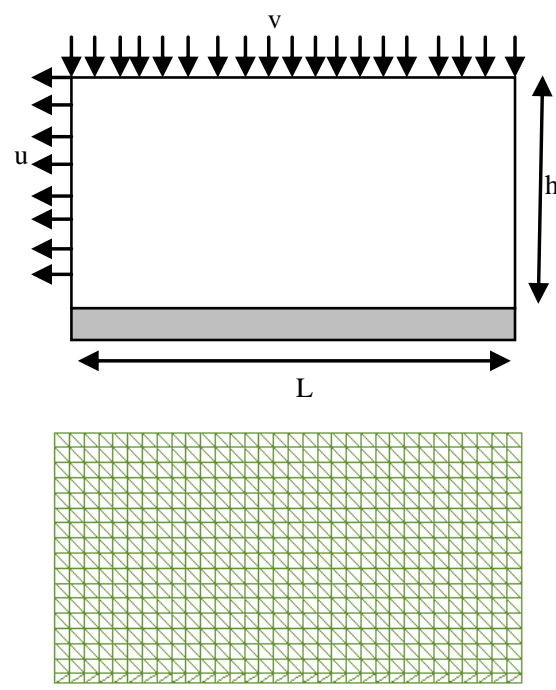

Fig.6 : Shear delamination of a block of aluminium

The block sizes are $\mathrm{L}=50 \mathrm{~mm}$ as length, $\mathrm{h}=25 \mathrm{~mm}$ as height. The Young modulus of the Aluminum block was $\mathrm{E}=6.9 \mathrm{E}+4 \mathrm{MPa}$. Poisson's ratio was $v=0.333$. The characteristics used in the numerical test are as follows: $w=1 . \mathrm{E}-3 \mathrm{~mJ} / \mathrm{mm}^{2} ; \mathrm{C}_{\mathrm{n}}=\mathrm{C}_{\mathrm{t}}=1.64 \mathrm{MPa} / \mathrm{mm}$; $\alpha=1 \mathrm{Ns} / \mathrm{mm} ; \mu=0.2$.
Initial conditions : $\beta=1, u_{n}=0$, and $\boldsymbol{u}_{t}=0$. The structure is discretized using linear triangular elements. The interface consists of 33 nodes and one used 210 time increments. The successive deformed meshes are displayed in figure 7 for times $\mathrm{t} 1=2.143 \mathrm{~s}, \mathrm{t} 2=3143$, and $\mathrm{t} 3=3.571 \mathrm{~s}$.

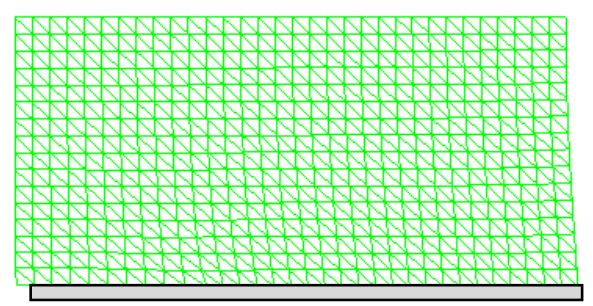

t1

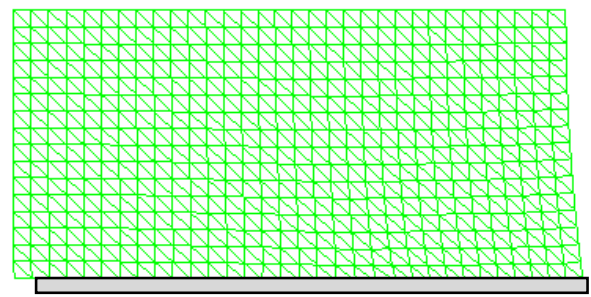

t2

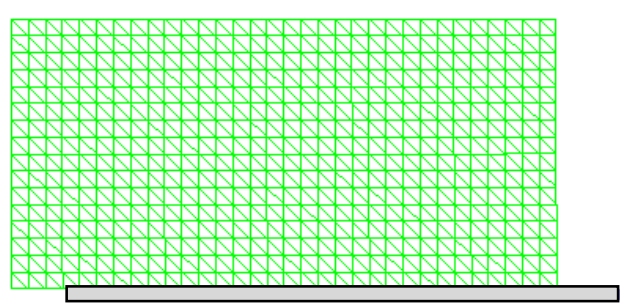

t3

Fig. 7 : Deformed meshes

In the figures below we have ploted along the interface, the evolution of debonding, tangential sliding and the adhesion intensity $\beta$ obtained by RCCM and bipotential models, for the given times $t_{1}, t_{2}$, and $t_{3}$. 

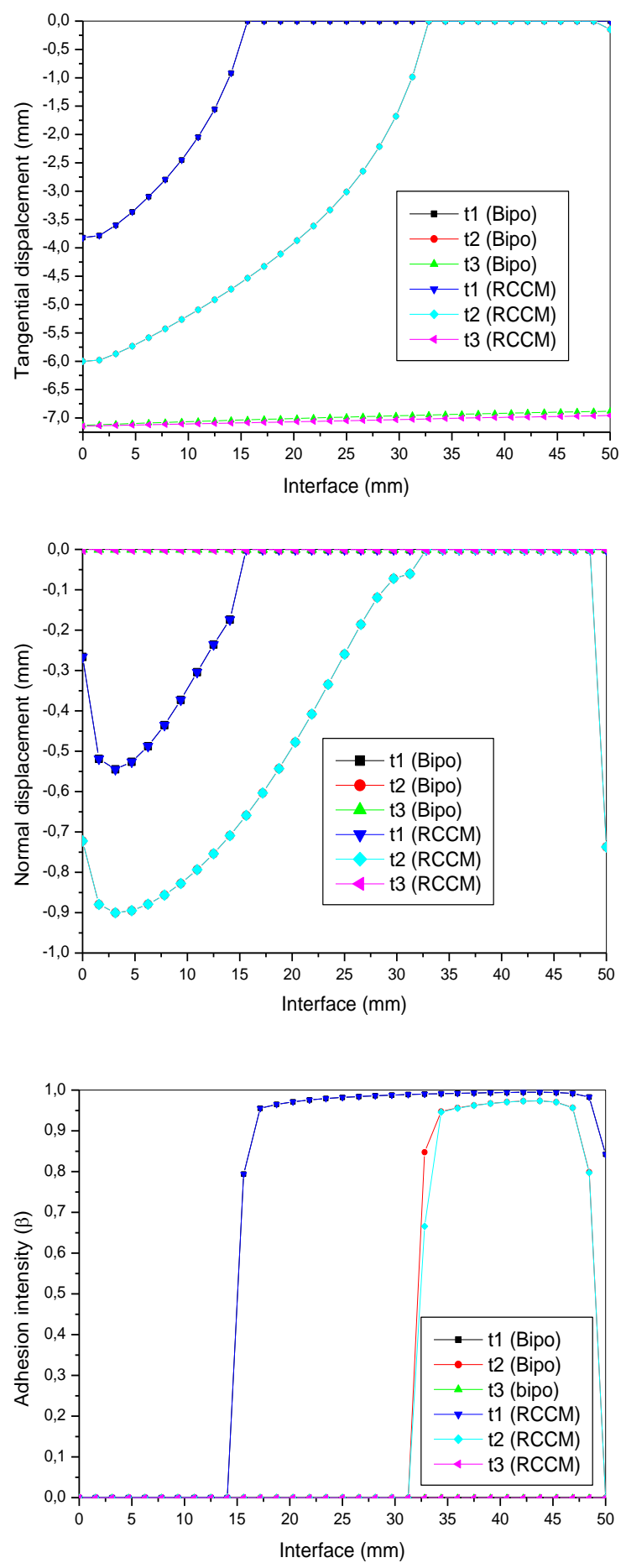

Fig 8 : The tangential displacement $\boldsymbol{u}_{\boldsymbol{t}}$, the normal displacement $u_{n}$, and the adhesion intensity $\beta$ along the interface for loading times: $t 1, t 2$ and $t 3$

In Figure 9, the contact conditions are presented. For a point of interface we have ploted the adhesive reaction Radh, and the contact reactions R. Let us now analyze the interface by considering the shear behavior (see Fig. 9). We suppose initially that we have a complete adhesion $(\beta=1)$ and zero displacement $\left(\mathrm{u}_{\mathrm{n}}=\mathrm{u}_{\mathrm{t}}=0\right)$.
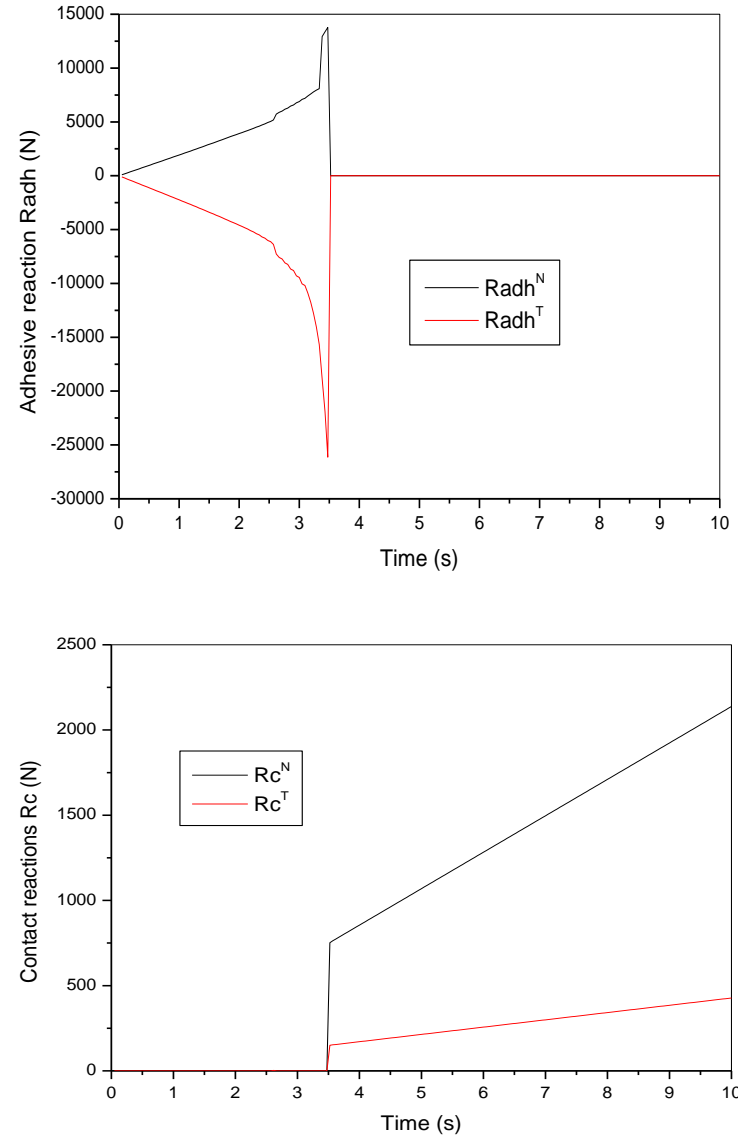

Fig. 9 : Contact forces

Under compression, the sliding limit is $\left(\bar{\mu}\left|R_{n}\right|\right)$ because $u_{n}=0$. As long as the norm of the tangential force is smaller than the sliding limit, sliding does not occur $\left(\boldsymbol{u}_{\boldsymbol{t}}=0\right)$ as initial condition and $\dot{\boldsymbol{u}}_{\boldsymbol{t}}=\boldsymbol{0}$ in expression (30). Under the lateral displacement $u$, an elastic tangential displacement occurs, and the sliding limit is reached. An adhesive resistance $\left(R_{a d h}=\int_{\Gamma_{c}} C \beta^{2} u d \Gamma_{c}\right)$ is

active and the tangential behavior is elastic with damage. When the displacement is sufficiently large, the elastic energy becomes larger than the limit of adhesion energy w and the adhesive limit is reached. After that, damage of the interface occurs and consequently, on the one hand, the intensity of adhesion $\beta$ starts to decrease which involve a reduction in the adhesive reactions until their complete vanishing, and on the other hand, friction begins to operate. When the adhesion is completely broken $(\beta=0)$, the usual Coulomb friction conditions are obtained. Table 2 summarizes the number of iterations and the computational times (total CPU time) for the two models. These results show once again the efficiency of the proposed method. 
TABLE 2 .

COMPARISON OF CONVERGENCE AND CPU TIME

\begin{tabular}{|c|c|c|c|c|c|c|c|c|c|}
\hline \multirow{2}{*}{ Model } & \multirow{2}{*}{ Parameters } & \multicolumn{7}{|c|}{ Steps } & \multirow{2}{*}{$\begin{array}{c}\text { GLOBAL CPU } \\
\text { (s) }\end{array}$} \\
\hline & & 1 & 10 & 40 & 60 & 100 & 150 & 200 & \\
\hline \multirow{3}{*}{ 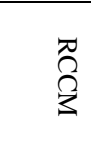 } & $\beta$ Iterations & 1 & 2 & 3 & 5 & 1 & 1 & 1 & \multirow{3}{*}{$8 \mathrm{~m}: 17 \mathrm{~s} .367 \mathrm{c}$} \\
\hline & Contact Iterations & 132 & 132 & 132 & 132 & 175 & 175 & 175 & \\
\hline & CPU (s) & 0.750 & 0.703 & 0.905 & 0.694 & 0.906 & 0.893 & 1.21 & \\
\hline \multirow{3}{*}{ 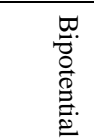 } & $\beta$ Iterations & 1 & 2 & 3 & 9 & 1 & 1 & 1 & \multirow{3}{*}{$2 \mathrm{~m} \mathrm{16s} \mathrm{50c}$} \\
\hline & Contact Iterations & 2 & 4 & 5 & 5 & 58 & 58 & 58 & \\
\hline & CPU (s) & 0.20 & 0.23 & 0.18 & 0.18 & 0.19 & 0.19 & 0.19 & \\
\hline
\end{tabular}

\section{Conclusion}

The RCCM model developed by Raous, Cangémi, Cocou and Monerie is a cohesive interface model taking into account strict unilateral contact to avoid the interpenetration of the two bodies in contact, initial adhesion which will progressively decrease when the loading increases, and Coulomb's friction which is progressively introduced when adhesion decreases. The model is based on thermodynamic considerations and surface interactions concepts. Because of its implicit character, the Coulomb friction law with adhesion in the RCCM model is non-associated, and the notion of superpotential with normality rule cannot be used anymore. To overcome this undesirable lack of normality, G. De Saxcé and Feng [17],[18] introduced the class of implicit standard materials (ISM) based on the concept of bipotential. A major result of the ISM theory was the possibility of representing many nonstandard dissipative laws by a suitable pseudopotential depending on the dual variables, internal variable rates and associated variables. The concept of bipotential is based on an extension of the Fenchel inequality, and is a generalization of the notion of pseudo-potential which enables us to write the evolution laws as implicit normality rules. The contact law is then written as a differential inclusion and the choice of a convenient bipotential allows us to uncover a normality rule. In this paper, by using a variational formulation of the frictional contact law based on the ISM concept, a bipotential formulation for the RCCM model, coupling adhesion and friction has been theoretically investigated and numerically implemented. It has shown that on the interface, the frictional contact law with adhesion described by a non-associated sliding rule and its inverse are obtained by applying the normality rule to a single scalar-valued function called a bipotential, which leads to a single displacement variational principle and a single inequality. The unilateral contact with adhesion and the friction with adhesion are coupled.
By doing so, the local stage involves only a single predictor-corrector step reducing significantly the computing time, where the developed algorithm, solves the contact problem iteratively in a reduced linear system and computes the displacements in the whole structure, using contact reactions as external loading. The algorithms developed have been implemented and tested in the finite element code SYMEF developed by Berga and Terfaya at FIMAS laboratory, at the University of Bechar. The ability of the framework was illustrated by simulations and the model is tested with benchmark for simulating delamination. Two examples considering normal and shear behavior of interface for a 2D case have been studied in detail. A comparative study has been made between the newly proposed model and the previously developed RCCM Model. The numerical test shows that both algorithms give same results, however the RCCM algorithm needs more iterations than the bipotential algorithm. The above results demonstrated that our model could provide better performance in terms of numerical stability and precision when compared to the RCCM Model for the local analysis of frictional contact problems. The Signorini conditions and Coulomb friction laws are quite well satisfied. The algorithms presented in this work can be extended in the future by taking into account other complex problems such as material non-linearities and it can be readily extended to dynamic contact problems.

\section{REFERENCES}

[1] SH. Chan, IS. Tuba, A finite element method for contact problems of solid bodies. Int. J. Mech. Sci., 13: 615-639, 1971

[2] T. Tsuta , S. Yamaji, Finite element analysis of contact problem, Theory and practice in finite element structural analysis. Proc. 1973 Tokyo seminar on element analysism, pp. 177-194, 1973

[3] B. Fredriksson, Finite element solution of surface nonlinearities in structural mechanics with special emphasis to contact and fracture mechanics problems. Comput. Struct. 6: 281-290, 1976 
[4] N. Kikuchi, JT. Oden,Contact problems in elastostatics (Oden JT, Carey GF (eds) Finite Elements, Vol. 5, Prentice- Hall, Englewood Cliffs, NJ, 1984)

[5] A. Francavilla, OC. Zienkiewicz, A note on numerical computation of elastic contact problems. Int. J. Numer. Meth. Eng. 9: 913-924, 1975

[6] TD. Sachdeva CV. Ramarkrishnan, A finite element solution for the two-dimensional elastic contact problems with friction. Int. J. Numer. Meth. Eng. 17: 1257-1271, 1981

[7] DH. Nguyen, G. De Saxcé, Frictionless contact of elastic bodies by finite element method and mathematical programming technique. Comput. Struct. 11: 55-67, 1980

[8] A. Klarbring, G. Björkman, A mathematical programming approach to contact problems with friction and varying contact surface. Comput. Struct. 30: 1185-1198, 1988

[9] WX. Zhong, SM. Sun, A parametric quadratic programming approach to elastic contact problems with friction. Comput. Struct. 32: 37-43, 1989

[10] KJ. Bathe, A. Chaudhary, A solution method for planar and axisymmetric contact problems. Int. J. Numer. Meth. Eng. 21: 6588,1985

[11] B. Nour-omid, P. Wriggers, (1986) A two-level iteration method for solution of contact problems. Comput. Meth. Appl. Mech. Eng. 54: 131-144, 1986

[12] M. Jean, G. Touzot, Implementation of unilateral contact and dry friction in computer codes dealing with large deformation problems. J. Theor. Appl. Mech. 7: 145-160, 1988

[13] P. Alart, A. Curnier, A mixed formulation for frictional contact problems prone to Newton like solution methods. Comput. Meth. Appl. Mech. Eng. 92: 353-375, 1991

[14] JC. Simo , TA. Laursen,(1992) An augmented Lagrangian treatment of contact problems involving friction. Comput. Struct. 42: 97-116,1992

[15] A. Klarbring, Mathematical programming and augmented Lagrangian methods for frictional contact problems. (In Curnier A (ed.), Proc. Contact Mechanics Int. Symp.PPUR, pp. 369-390, 1992)

[16] JH. Heegaard, A. Curnier,(1993) An augmented Lagrangian method for discrete large slip problems. Int. J. Numer. Meth. Eng. 36: 569-593, 1993

[17] G. De Saxcé, Z.Q. Feng, New inequality and functional for contact with friction: The implicit standard material approach. Mech. Struct. Mach. 19: 301-325, 1991

[18] G. De Saxcé, Z.Q. Feng, The bipotential method : a constructive approach to design the complete contact law with friction and improved numerical algorithms, Math. Comput. Modelling, 28, No 4-8, pp.225-245, 1998

[19] P. Joli, Z.Q. Feng, Uzawa and Newton algorithms to solve frictional contact problems within the bi-potential framework, Int. J. Numer. Meth. Engng 73, 317-330,2008

[20] M. Raous, L. Cangémi, M. Cocou, A consistent model coupling adhesion, friction and unilateral contact, Comput. Methods Appl. Mech. Engrg. 177, pp.383-399, 1999.

[21] M. Raous, Y. Monerie, Unilateral contact, friction and adhesion: 3D cracks in composite materials ( in: J.A.C. Martins, M.D.P. Monteiro Marques (Eds.), Contact Mechanics, Kluwer, Dordrecht 2002 , pp. 333-346).

[22] M. Frémond, Adhérence des solides, J. Méc. Théor. Appl. 6 (3),pp.383-407, 1987

[23] M. Frémond, Contact with adhesion, in: J.-J. Moreau, P.D. Panagiotopoulos (Eds.), Nonsmooth Mechanics and Applications (in: CISM Courses and Lectures, vol. 302, Springer, Wien, 1988, pp. 177-221)

[24] L. Cangémi, Frottement et adhérence : Frottement et adhérence: modèle, traitement numérique et application à l'interface fibre/matrice. Thèse de doctorat, Institut de Mécanique de Marseille, 1997.

[25] M. Raous, L. Cangémi and M. Cocu, Un modèle couplant adhérence et frottement pour le contact entre deux solides déformables. Cptes. Rend. Acad. Sc. Paris, 325 Série IIb, pp.503509, 1997

[26] N. Terfaya., Contribution à la modélisation des problèmes de contact et de frottement bi-dimensionnels, Mémoire de magister, Centre Universitaire de Bechar, Algérie, 2000
[27] A. Berga, N. Terfaya, Modélisation de la plasticité des sols et du phénomène de contact avec frottement par l'approche de matériaux standards implicites, Colloque International GECOTEC, 11-12 Octobre 2003, Alger, Algérie.

[28] A. Berga et N. Terfaya, Architecture des logiciels de simulation, Annales de l'université de Béchar Algérie, $N^{\circ} 1,2005$

[29] Y. Monerie, Fissuration des matériaux composites : rôle de l'interface fibre/matrice, Thèse doctorat, Université. Provence, Marseille, 2000

[30] M. Raous, M.A. Karray, Model coupling friction and adhesion for steel-concrete interfaces, Int. J. Comput. Appl. Technol. 34 (Issue 1), 42-51, 2009.

[31] F. Fouchal, F. Lebon, I. Titeux, Contribution to the modelling of interfaces in masonry construction, Constr. Build. Mater. 23 (Issue 6)2428-2441, 2009

[32] N. Terfaya, M. Raous, A. Berga, Cohesive zone model and bipotential formulation: application to a pile/soil interface, in: Proceedings of the 3rd Euro Mediterranean Symposium on Advances in Geomaterials and Structures, pp. 45-50, 2010

[33] A.Berga,G. De Saxcé, Elastoplastic finite element analysis of soil problems with implicit standard material constitutive laws, Revue européenne des éléments finis 3,411-456,1994

[34] A. Berga, Mathematical and numerical modeling of the nonassociated plasticity of soils-Part 1:The boundary value problem, International Journal of Non-Linear Mechanics 47.26 $35,(2012$

[35] A. Berga, Mathematical and numerical modeling of the nonassociated plasticity of soils-Part 2:Finite element analysis, International Journal of Non-Linear Mechanics 4, 36-45,2012

[36] M. Jean, V. Acary, Y. Monerie, Non-smooth contact dynamics approach of cohesive materials, Philosophical Transactions: Mathematical, Physical Engineering Sciences, Royal Society, London A 359 (1789)2497-2518,2001.

[37] V. Acary, Contribution la modélisation mécanique et numérique des édifices maçonnés. Thèse, Jean, M., supervisor, Université de la Méditerranée, Marseille,2001.

[38] Y. Monerie, V. Acary, Formulation dynamique d'un modèle de zone cohésive tridimensionnel couplant endommagement et frottement, Rev. Eur. Elem Finis, 10, PP 489-504, 2001

[39] V. Acary, Y. Monerie, Nonsmooth fracture dynamics using a cohesive zone model, INRIA report n6032, 56 pp. (ISSN 0249. 6399), 2006.

[40] G. Duvaut, J.L. Lions, Les inéquations en mécanique et en physique, (Dunod, Paris, 1972)

[41] N. Kikuchi and J.T. Oden J.T.,Contact Problems in Elasticity : A Study of Variational Inequalities and Finite Element Methods,(SIAM, Studies in Applied Mathematics, Philadelphia, 1988)

[42] Z. Q. Feng, 2D or 3D frictional contact algorithms and applications in a large deformation context. Communications in Numerical Methods in Engineering 11:409-416, 1995

[43] Z. Q. Feng Z-Q, F. Peyraut F,N. Labed , Solution of large deformation contact problems with friction between Blatz-Ko hyperelastic bodies. International Journal of Engineering Science 41:2213-2225, 2003

[44] M. Raous, Quasi-static Signorini problem with Coulomb friction and coupling to adhesion, (In Wriggers P., and Panagiotopoulos, P.D. editors, New developpements in contact problems, CISM courses and lecture, $\mathrm{N}^{\circ} 383$ Springer 101-178., 1999)

[45] M. Raous, V. Belloeil, I. Rosu, Modélisation de l'adhésion par collage, Rapport interne, LMA et LCPC, 2004

[46] M. Schryve, Modèle d'adhésion cicatrisante et applications au contact verre/élastomère, Thesis, M. Raous, M. Cocou (Adv.), Univ. Provence, 2008

[47] G. ANTONI, Localisation de rupture au voisinage d'interface : couplage d'endommagement volumique et surfacique, rapport interne, LMA, Marseille, 2007

[48] J.C. Latil, M. Raous, Module Gyptis version 1.0. Contact unilatéral avec frottement en mécanique des structures. (Inéquations variationnelles, Publication du L.M.A., Notes Scientifiques, 132, CNRS., 1991) 


\section{Authors' information}

${ }^{1}$ Laboratoire de Fiabilité des Matériaux et des Structures, Université

TAHRI Mohamed Béchar, B.P. 417, 08000, Algérie

Tel/Fax: 213664699 555; Fax: 21349815244

Email : t_nazihe@yahoo.fr

bergaabdelmadjid@yahoo.fr

${ }^{2}$ Laboratoire de Mécanique et d'Acoustique (UP 7051) 31, chemin

Joseph Aiguier 13402 Marseille Cedex 20 - France

Email: raous@1ma.cnrs-mrs.fr

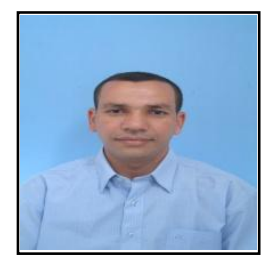

N. Terfaya (1972), Mechanical engineer (1994), and Magister in Mechanical engineering (2000) of Bechar University, Algeria.

Resarch interests are frictional contact, interface problem, soil-structure interaction, fluid-structure interaction, non linear analysis, structures modeling and simulation by finite element method, oriented object programming (MEF++)

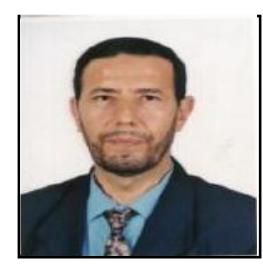

A. Berga (1963). Civil engineer (1987) of Oran University, Algeria. Dr. (1993) of Compiègne University of technology (French).

Research interests are soil mechanics, non linear analysis, structures modeling and simulation by finite element method, data base for scientific software, plasticity, frictional contact and structural dynamic

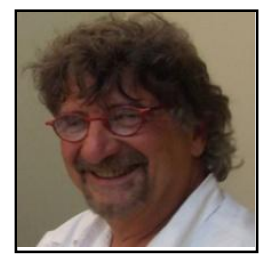

M. Raous (1947). Director of Research, LMA Marseille CNRS, Master of Science (1970), Engineer from the National School of Physics (1970), Doctor-Engineer (1973),Doctor (1980)

Research interests are frictional contact problem, interface problem, structural dynamic and contact dynamic 